\title{
Assessment of Reductions in Emission-driven Air Pollution during the Beijing Olympic Games, \\ Shanghai World Expo, Guangzhou Asian Games and Wuhan COVID-19 Lockdown
}

Aerosol and Air Quality Research

Special Issue:

Special Issue on COVID-19 Aeroso Drivers, Impacts and Mitigation (XVII)

\author{
Ying $\mathbf{L i}^{1,2^{*}}$, Haoxiang $\mathrm{Xu}^{1}$ \\ ${ }^{1}$ Department of Ocean Science and Engineering, Southern University of Science and Technology, \\ Shenzhen, China \\ ${ }^{2}$ Center for Oceanic and Atmospheric Science at SUSTech (COAST), Southern University of \\ Science and Technology, Shenzhen, China
}

\section{ABSTRACT}

Quantifying and comparing the effectiveness of different emission control strategies can provide insights for policy design and air quality management. In our previous work, we developed a windpollution decomposition (WPD) method that provides a robust tool to quantify meteorology-driven and emission-driven impacts on changes in air quality. In this study, we applied this method to quantify emission-driven impacts on the observed air quality changes during the three largest international socioeconomic mega-events in China, namely, Shanghai World Expo in 2010, Beijing Olympic Games in 2008, and Guangzhou Asian Games in 2010. We also applied the method to the air quality variation during the lockdown period in Wuhan due to COVID-19 and compared the emission-driven impacts on air quality among these events. The results quantitatively show that the emission-driven factor generally played a much stronger role (> 86\%); the meteorologydriven factor promoted pollution mitigation during Wuhan, Beijing and Guangzhou events but worsened the air quality during Shanghai event. The emission-driven pollution reduction was largest in the Wuhan COVID-19 lockdown (64\% NO $2,54 \% \mathrm{PM}_{2.5}$ reductions), followed by Beijing Olympics (42\% $\mathrm{PM}_{2.5}, 31 \% \mathrm{NO}_{2}$ reductions), The Wuhan COVID-19 impact on air quality improvement is not as effective as expected especially for $\mathrm{O}_{3}$, which implies the difficulty of air quality attainment under normal, non-lockdown days. Comparison of these events show that shutdown or emission control measures applied to industries and power plants were generally benefit for $\mathrm{PM}_{2.5}, \mathrm{SO}_{2}$ and $\mathrm{NO}_{2}$ reduction, while those applied to on-road traffic control are lesseffective for reducing $\mathrm{NO}_{2}$ and not works for the mean $\mathrm{O}_{3}$ reduction. The results imply that advanced control measures for vehicle exhaust and control strategies considering the interaction between $\mathrm{O}_{3}$ and $\mathrm{NO}_{x} / \mathrm{VOC} / \mathrm{PM}$ are necessary. In addition, the ongoing supervision of control strategies implementation is one of the key issues for future air quality management in China.

Keywords: Emission controls, Effectiveness, Mega-events, $\mathrm{PM}_{10}, \mathrm{O}_{3}$

\section{INTRODUCTION}

The haze and photochemical smog events that have occurred frequently since 2010 in the key city clusters of China, such as, the Yangtze River Delta (YRD), the Pearl River Delta (PRD) and JingJin-Ji (JJJ), indicate a significant regional air quality issue in China. To improve air quality and protect public health, different administrative levels of government have implemented a range of intervention programmes to reduce anthropogenic emissions. In the Action Plan for Air Pollution Prevention and Control (i.e., the 'National Ten Measures') (MEP, 2013), instead of targeting reductions in emission amounts, the Chinese government targeted direct reductions in air 
pollution concentrations, especially for the three most polluted regions, JJJ, YRD and PRD.

To adjust policy recommendations in time, the effectiveness of policies for controlling ambient air quality must be assessed within a relatively short period (e.g., at the inter-annual scale). In China, government agencies report the national air quality annually or semi-annually to review the success or failure of the related efforts. Therefore, it is of interest to investigate the impacts of implemented control strategies on air quality at the same time scale. However, the impact of emission control is generally difficult to quantify at this scale since the impact is often intertwined with the impact of pollution transported via meteorological factors. The impacts of regional or superregional pollution transport, as well as those of local emission dispersion, are all subject to ambient wind conditions, which change significantly at the synoptic scale and notably at the inter-annual scale (Katsoulis, 1988; Wang et al., 1998; Chung et al., 1999; Lo et al., 2006; Gietl and Klemm, 2009; Li et al., 2012a). For example, in a year, the higher frequency of weak wind will lead to a deterioration of air quality even though there is no emission increase compared to the previous year (Lo et al., 2006; Gietl and Klemm, 2009).

In general, without aggressive intervention control programmes, the separation and evaluation of emission-driven and meteorology-driven changes in inter-annual air quality is very difficult, since the change in air quality due to emission-driven impacts could be small and difficult to differentiate from the changes caused by other impacting factors. However, during mega-events in China that employed aggressive intervention strategies for periods of several months to control emissions, emission-driven factors likely made the dominant contribution to air quality improvement. In addition to the COVID-19 lockdown period in Wuhan, which resulted in significant emission reductions, the Beijing Olympic Games in 2008, the Shanghai World Expo in 2010, and the Guangzhou Asian Games in 2010 are the three largest international socioeconomic mega-events in China that have resulted in lasting aggressive emission abatement (Lin et al., 2013a); these events represent good opportunities to evaluate the emission-driven and meteorology-driven impacts on air quality changes, and to assess the effectiveness of different control strategies applied. Notable air quality improvement was reported for the Beijing Olympic Games (Wang et al., 2009a; Mijling et al., 2009; Wang et al., 2009c; Chen et al., 2013; Gao et al., 2013; Li et al., 2013a; Wang et al., 2013; Wang et al., 2014; Liu et al., 2015a; Liu et al., 2015b; Yang et al., 2015; Norra et al., 2016), the Shanghai World Expo (Fu et al., 2011; Hao et al., 2011; Huang et al., 2012; Cheng et al., 2013; Huang et al., 2013; Lin et al., 2013b), and the Guangzhou Asian Games (Li et al., 2012b; Liu et al., 2013; Xu et al., 2013; Yao et al., 2013; Lin et al., 2014; Tao et al., 2015). Significant variation in pollution levels $\left(61 \%, 25 \%, 20 \%\right.$, and $21 \%$ for daytime $\mathrm{SO}_{2}, \mathrm{CO}, \mathrm{O}_{3}$, and $\mathrm{NO}_{x}$ reduction, respectively) were observed in August 2008 compared to August 2006-2007 in the Beijing urban area (Wang et al., 2009b). For the Shanghai Expo, the daily average concentrations of $\mathrm{PM}_{10}, \mathrm{SO}_{2}$ and $\mathrm{NO}_{2}$ decreased by $25.0 \%, 10.9 \%$ and $18.1 \%$, respectively, compared with those in the same period in 2009 (Fu et al., 2011). Reductions of $12.84 \%, 8.84 \%, 28.17 \%$ and $23.31 \%$ were observed for $\mathrm{NO}_{2}, \mathrm{O}_{3}, \mathrm{PM}_{10}$, and $\mathrm{SO}_{2}$, respectively, during the Asian Games period (Li et al., 2012b). In addition, the COVID-19 lockdown in Wuhan city in 2020 also provides an opportunity to easily validate the results of differentiating emission-driven changes from meteorology-driven changes in air quality. Due to the rapid outbreak of COVID-19, the megacity of Wuhan, which has a population of more than ten million, underwent a lockdown that lasted for 76 days. The Wuhan lockdown led to a substantial reduction in economic damage and local emissions during the lockdown period (Bherwani et al., 2020; Le et al., 2020). To quantify the emission-driven effect on air pollution reduction during the four events, it is necessary to separate the meteorology-driven effect from the air quality variation. Some studies have reported the emission-driven effect for a specific event and identified the emission-driven contribution. However, most of these results are dependent on complex subjective data analysis for a specific case or unconventional observations (Huang et al., 2013), and it is difficult to quantitatively acquire and compare the emission-driven contributions for the different events; nonetheless, such assessment and comparisons of different events have crucial environmental policy implications for mitigating air pollution and benefitting public health.

In our previous work (Li et al., 2014), we developed a wind-pollution decomposition method (WPD) that provides an objective and effective tool to quantify meteorology-driven and emissiondriven impacts on air quality changes at the inter-annual scale and that does not depend on the subjective parameter selection or emission factor construction. In this study, we used this WPD 
method to quantify the effectiveness of the integrated control programmes implemented in the three largest international social events in China and the passive emission reduction due to the COVID-19 event in Wuhan. The emission-driven and meteorology-driven impacts on the observed air quality changes during these events were quantified and compared based on the best available observational data. Based on the quantified results with this objective and robust method, we first compare the control effectiveness of the different mega-events together. The remainder of this paper is organized as follows. In Sect. 2, we describe the observational dataset and the methodology used in the analysis. In Sect. 3, we present and discuss the decomposition results for the Beijing Olympic Games in 2008, the Shanghai World Expo in 2010, the Guangzhou Asian Games in 2010 and the COVID-19 event in 2020. In the conclusion section, we summarize the results.

\section{DATA AND METHODOLOGY}

Beijing hosted the Summer Olympic Games from 8 to 24 August, 2008, and hosted the Paralympic Games from 9 to 17 September, 2008; these events were the first and largest international megaevent in China at that time. The national government made a first attempt to improve the air quality during this period by carrying out a series of intervention programmes, such as closing or relocating industrial plants, decreasing local power generation, suspending construction, promoting natural gas usage, implementing strict traffic restrictions, and other interventions. The Shanghai World Expo was held from 1 May to 31 October 2010. It is the longest international event ever held in China. In total, 73 million visitors attended this mega-event. Shanghai is located at the eastern tip of the YRD, which is made up of the largest contiguous metropolitan areas in the world. The YRD region comprises the megacity of Shanghai and many other cities in Jiangsu and Zhejiang provinces; it is also one of the most industrial regions in China, contributing approximately $21.4 \%$ of the national gross domestic product (GDP) (UNEP, 2009). Guangzhou hosted the Asian Games from 12 to 27 November 2010, and the Asian Para Games from 12 to 19 December 2010. Guangzhou is located at the center of the PRD, which is one of the most rapidly developing regions in China. The area included Guangzhou, Hong Kong, Macau, and 8 other cities is called the PRD economic zone (PREZ). The PREZ is one of China's leading economic regions and a major manufacturing center. A total of $4.2 \%$ of the total Chinese population live in the PREZ, and the PREZ generates $9.3 \%$ of the GDP in China. It is the largest urban area in the world (World Bank, 2015). COVID-19, officially called coronavirus disease 2019, initially broke out in the city of Wuhan, China, in December 2019 and appeared all around the world in the next year. Due to the severity of the outbreak, the Chinese government decided to temporarily quarantine Wuhan city to prevent the spread of the disease. During the lockdown period, only production activities that were closely related to residents' basic living requirements, such as vegetable processing, were allowed to continue. The lockdown began from 23 January, ended on 8 April 2020. According to an announcement from the national government, factories and enterprises were not allowed to return to production until 21 March. Therefore, this strict lockdown created a unique 58-day period in which pollutant emissions should be very low. Meteorology data was from the closest Global Telecommunications System (GTS) stations. Hourly air pollution data was taken from national air quality monitoring stations. Due to limitations on data availability, we do not have every pollutants for all the events. The data available for this work are summarized in Table S1. Detailed data information for individual events and geographical position are also provided in the Supporting Information (SI).

With the WPD method, we can decompose the mean variation in pollutant concentrations between two periods into a wind contribution (representing the meteorology-driven contribution), a non-wind contribution (representing the emission-driven contribution), and a non-linear term. In this method, a linear index $L$ is defined and validated by the Monte Carlo method to show the relative importance of each linearly decomposed contribution. A result with $L>0.87$ is considered significant at a $90 \%$ confidence level. The decomposition analysis is only applied for the cases if the expectation value of the concentration average is within $5 \%$ difference compared to the average value calculated based on the original time series. Before the analysis, we also carried out following checking steps to avoid impact of data contamination. (1) Remove uncompleted data in group (e.g., if data of wind direction missed, data of wind speed and pollutant will not be 
induced into the decomposition analysis); (2) exclude inconsistent data (for example, pollutant concentration suddenly drop to zero); (3) exclude data from specific station that has too many missing (or in-consequent) data. The details of the method can be referred to Li et al. (2014). We also specify the key principles of the decomposition method in the Supporting Information (SI) in order to provide a self-contained study. The uncertainties of applying wind to represent meteorology, and non-wind to represent emission-driven is limited in these events and discussed in Sect. 4.

\section{RESULTS AND DISCUSSION}

\subsection{Analysis for 2010 Shanghai World Expo}

We first present the analysis for the Expo event as an example to show clearly how WPD can be applied to analyze and evaluate the effectiveness of control programs on air quality. The WPD analysis method was applied to decompose the pollution variation between the mean pollutant concentration values during the Expo period (1 May-30 November) of 2010 (control period) compared to the same period of 2009 (pre-control period). Several air quality stations were selected to represent air pollution in Shanghai (see Fig. S1): PuDong station (PD) located in the east of urban area; DianShan Lake station (DSL) located at the southwest boundary of Shanghai; and a city average which is the mean concentration of other stations.

Wind Roses and PM 10 Pollution Rose Pattern Analysis: The wind roses (Figs. 1(a) and 1(b)) show that the winds are dominated by southeasterly in both 2009 and 2010 . The change in the wind roses from 2009 to 2010 (Fig. 1(c)) shows more southeasterly while less others in 2010. The pollution roses (Figs. 1(d) and 1(e)) show that there is higher pollution levels from the northwest and southwest side and lower pollution level from the eastern side, which indicates the polluted air mass transport from the western China Central Plain (Huang et al., 2012; Lin et al., 2013b) and the cleaner air mass brought by the easterly from the sea. Pollution Rose can clearly show the direction of the impacting source to the receptor station by transport, while it is hard to quantitatively identify the source distance by wind speed. But generally speaking, the weak winds are more relevant to local/regional emission effect, while the wind with high speed can bring the regional/super-regional pollutants. Compared with pollution rose of 2009 (Fig. 1(d)), the pollution rose difference is shown in Fig. 1(f). The pollution concentration of 2010 decrease significantly in northwest direction almost in all wind speeds, which indicates a reduced emission contribution of the regional and even super-regional transport from northwest; in southwest direction, the pollution concentration of 2010 decreased with low to middle wind speed, and increased with relatively high wind speed (Fig. 1(e)), which indicates an emission reduction in local and regional sources, but an increased emission contribution by long-term transport from southwestern side. In addition, the $\mathrm{PM}_{10}$ concentration is much lower in low wind speed (less than $2 \mathrm{~m} \mathrm{~s}^{-1}$ ) than those in higher wind speed in 2010, which indicate a greater effort from local emission control than that in non-local areas in 2010.

Emission-driven Effect of PM Pollutant: the non-wind effect on $\mathrm{PM}_{10}$ concentrations (Fig. 1(h)) during the Expo event can be estimated from the spatial product of the wind rose of 2009 (Fig. 1(a)) and the difference between the pollution roses (Fig. 1(f)). Fig. 1(h) shows that the pollution concentration (emission contribution) was reduced in most directions especially from the western side to Shanghai during the Expo event. This result is the expected result of the air quality control strategies implemented for the Expo event, which included the fugitive dust control measures, reductions in coal burning at power plants, the closure of highly polluting factories and strict emission standards for vehicles (Huang et al., 2012). However, we also found an unexpected increase in pollution to the southeast at low to moderate wind speeds, which indicates that there was an unexpected increase in $\mathrm{PM}_{10}$ emissions from the south-eastern part of Shanghai (Feng Xian district) or there was an unexpected increase in $\mathrm{PM}_{10}$ emissions from the south-western area of Shanghai and the neighboring rural area of Zhejiang Province, where are relatively undeveloped areas that produced mainly agricultural emissions and very limited chemical industrial emissions before 2011. Huang et al. (2013) reported an increase in open biomass burning in the summer and autumn of 2010 (compared to that in 2009) on the south-eastern Shanghai and/or northern Zhejiang Province, where widespread fire spots with MODIS was detected in these 

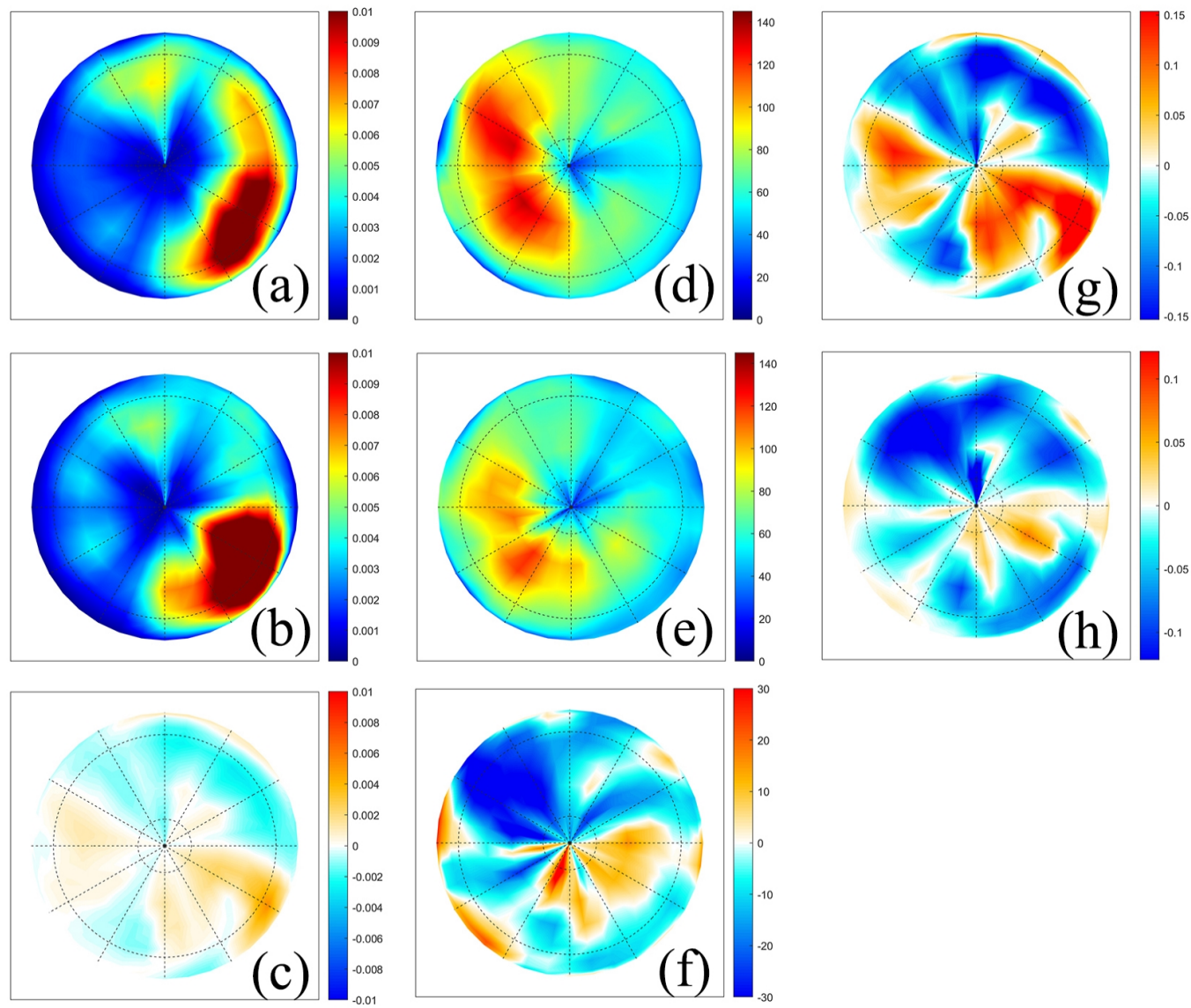

Fig. 1. Wind and $P M_{10}$ pollution roses at DSL of Shanghai (up direction as north): (a) wind rose of 2009; (b) wind rose of 2010; (c) change in wind rose from 2009 to 2010, (d) pollution rose of 2009 (unit: $\mu \mathrm{g} \mathrm{m}^{-3}$ ), (e) pollution rose of 2010 (unit: $\mu \mathrm{g} \mathrm{m}^{-3}$ ), (f) change in pollution rose from 2009 to 2010 (unit: $\mu \mathrm{g} \mathrm{m}^{-3}$ ), (g) wind effect (unit: $\mu \mathrm{g} \mathrm{m}^{-3}$ ); (h) non-wind effect (unit: $\mu \mathrm{g} \mathrm{m}^{-3}$ ). The wind rose shows the normalized frequency distribution of wind as a function of speed and direction; pollution rose shows the corresponding average pollutant concentration as a function of wind speed and direction of individual groupings. The small circle represents the $2 \mathrm{~m} \mathrm{~s}^{-1}$ wind speed and the large circle represents the $8 \mathrm{~m} \mathrm{~s}^{-1}$ wind speed.

regions; and high correlation between $\mathrm{PM}_{2.5}$ and $\mathrm{K}^{+}$, a typical tracer for biomass burning, was found during the biomass burning episodes; they consequently point out the ineffective control strategies of biomass emission during the Expo. Considering the derived biomass burning impact in Huang et al.'s (2013) study, we believe that the unexpected increase in non-wind PM10 pollution in the SE and SW direction reflects a failure to completely control biomass burning emissions from south-western Shanghai and northern Zhejiang Province, although the ban of open biomass burning issued was a regional-joint statute by the Shanghai, Jiangsu, and Zhejiang governments during the Expo period. This result shows that the ongoing supervision of control strategies is important for air quality management. Meanwhile, this case is an excellent example of the strength of this WPD method for capturing changes in integrated emissions using only routine air quality and meteorological data, which are easily obtained from open sources (e.g., national air quality monitoring networks and global telecommunications systems).

To explore the relative contributions of the wind and non-wind factors, the percentages of wind, non-wind and non-linear effects relative to the changes in $\mathrm{PM}_{10}, \mathrm{SO}_{2}$, and $\mathrm{NO}_{2}$ concentrations and the linear index ( $L$ index) for the expo period were then calculated and are provided in Table 1. As shown in Table 1, during the Expo period, the non-wind effect was the dominant factor in pollution mitigation during the Expo period ( $85 \%$ to $146 \%$ ), except for $\mathrm{NO}_{2}$ pollution at the PD station $(116 \%)$; the wind contribution was very small (1\% to $24 \%$ ) and was even a factor aggravating the $\mathrm{SO}_{2}$ and $\mathrm{NO}_{2}$ pollution at the DSL station ( $13 \%$ and $5 \%$ ). These results indicate the 
Table 1. The decomposition result in Shanghai during the Expo period (compared with the corresponding time period of the previous year).

\begin{tabular}{|c|c|c|c|c|c|c|c|c|c|}
\hline $\begin{array}{l}\text { Pollutant } \\
\text { Station }\end{array}$ & $\begin{array}{l}\mathrm{SO}_{2} \\
\mathrm{PD}\end{array}$ & $\begin{array}{l}\mathrm{SO}_{2} \\
\text { city }\end{array}$ & $\begin{array}{l}\mathrm{SO}_{2} \\
\mathrm{DSL}\end{array}$ & $\begin{array}{l}\mathrm{NO}_{2} \\
\mathrm{PD}\end{array}$ & $\begin{array}{l}\mathrm{NO}_{2} \\
\text { city }\end{array}$ & $\begin{array}{l}\mathrm{NO}_{2} \\
\mathrm{DSL}\end{array}$ & $\begin{array}{l}\mathrm{PM}_{10} \\
\mathrm{PD}\end{array}$ & $\begin{array}{l}\mathrm{PM}_{10} \\
\text { city }\end{array}$ & $\begin{array}{l}\mathrm{PM}_{10} \\
\mathrm{DSL}\end{array}$ \\
\hline$C 1$ & 36.37 & 29.5 & 36.74 & 41.39 & 47.91 & 49.31 & 77.44 & 73.84 & 77.16 \\
\hline$\Delta C$ & -7.58 & -4.9 & -2.96 & 2.5 & -1.02 & -5.01 & -7.56 & -2.16 & -2.84 \\
\hline Non-wind effect & $\begin{array}{l}-89 \% \\
(-6.75)\end{array}$ & $\begin{array}{l}-85 \% \\
(-4.17)\end{array}$ & $\begin{array}{l}-108 \% \\
(-3.20)\end{array}$ & $\begin{array}{l}116 \% \\
(2.90)\end{array}$ & $\begin{array}{l}-101 \% \\
(-1.03)\end{array}$ & $\begin{array}{l}-105 \% \\
(-5.26)\end{array}$ & $\begin{array}{l}-104 \% \\
(-7.86)\end{array}$ & $\begin{array}{l}-146 \% \\
(-3.15)\end{array}$ & $\begin{array}{l}-73 \% \\
(-2.07)\end{array}$ \\
\hline Wind effect & $\begin{array}{l}-2 \% \\
(-0.15)\end{array}$ & $\begin{array}{l}-2 \% \\
(-0.10)\end{array}$ & $\begin{array}{l}13 \% \\
(0.38)\end{array}$ & $\begin{array}{l}-24 \% \\
(-0.6)\end{array}$ & $\begin{array}{l}-1 \% \\
(-0.01)\end{array}$ & $\begin{array}{l}5 \% \\
(0.25)\end{array}$ & $\begin{array}{l}-12 \% \\
(-0.91)\end{array}$ & $\begin{array}{l}19 \% \\
(0.58)\end{array}$ & $\begin{array}{l}-15 \% \\
(-0.43)\end{array}$ \\
\hline Nonlinear effect & $-9 \%$ & $-13 \%$ & $-5 \%$ & $8 \%$ & $2 \%$ & $0 \%$ & $16 \%$ & $27 \%$ & $-12 \%$ \\
\hline$L$ index & 0.91 & 0.87 & 0.96 & 0.95 & 0.98 & 1.00 & 0.88 & 0.86 & 0.88 \\
\hline$C-L$ & 0.94 & 0.9 & 0.98 & 0.97 & 0.99 & 0.99 & 0.91 & 0.89 & 0.91 \\
\hline
\end{tabular}

Note: Unit of $C 1$ and $\Delta C$ : for $\mathrm{SO}_{2}$ and $\mathrm{NO}_{2}$ are ppb, for $\mathrm{PM}_{10}$ is $\mu \mathrm{g} \mathrm{m}^{-3} . C 1$ means the averaged concentration of pre-control period. Years with negative $\Delta C$ mean that the annual mean $\mathrm{PM}_{10}$ concentration deceased compared to the previous year, and vice versa. If the decomposed effect has a same sign with the $\Delta C$, it means the effect of this factor plays a positive role on the pollution change, and vice versa. Please note the linear decomposition results of $\mathrm{PM}_{10}$ in 'city' with $L<0.87$ does not satisfy $90 \%$ confidence level. " $C-L$ " indices are the confidence level from the Monte Carlo simulation and dimensionless.

success of control strategies to reduce $\mathrm{PM}_{10}$ and $\mathrm{SO}_{2}$ concentrations and the failure of urban $\mathrm{NO}_{2}$ control strategies.

Effectiveness of the Stationary and Mobile Source Control: The $\mathrm{SO}_{2}$ and $\mathrm{NO}_{2}$ pollution roses at the same urban station in Shanghai in 2009 and 2010 are plotted in Figs. 2(a)-(c) and Figs. 2(d)2(f), respectively. By comparing Fig. 1(f) with Figs. 2(c) and 2(f) we have: the $\mathrm{SO}_{2}$ concentration had a more uniform decreasing pattern than the $\mathrm{PM}_{10}$ from 2009 to 2010, while the mean concentration of $\mathrm{NO}_{2}$ was dominated by an overall increasing pattern. The above pollution rose's difference between 2010 and 2009 indicates the control policies for $\mathrm{PM}_{10}$ and $\mathrm{SO}_{2}$ is effective but ineffective for $\mathrm{NO}_{2}$. This result is consistent with the study of Lin et al. (2013b), which reported that Shanghai experienced low $\mathrm{SO}_{2}$ and $\mathrm{PM}_{10}$ levels but high $\mathrm{NO}_{2}$ and $\mathrm{O}_{3}$ levels during the Expo period. An increase in $\mathrm{NO}_{2}$ (2.5 ppb) was observed at the PD station. The decomposition results show that the increase in $\mathrm{NO}_{2}$ was $116 \%$ dominated by non-wind factors, which indicates even an increase in $\mathrm{NO}_{2}$ emissions in urban areas.

To investigate the cause of the failure control of urban $\mathrm{NO}_{2}$, we further apply the WPD on the ratio of $\mathrm{SO}_{2}$ to $\mathrm{NO}_{2}$, as an indicator to reflect the impact of stationary sources relative to that of mobile sources (Nirel and Dayan, 2001). Nirel and Dayan found that the ratio of $\mathrm{SO}_{2} / \mathrm{NO}_{2}$ had a typical relationship along mobile source. It should be applicable in this case because the urban $\mathrm{NO}_{2}$ emission mainly released from the stationary source and on-road mobile sources, while $\mathrm{SO}_{2}$ emission is mainly from stationary source during Expo. For the stationary source, in order to accomplish the environment protection goal of the Eleventh Five-Year Plan (MEP, 2006), flue-gas desulfurization (FGD) control for $\mathrm{SO}_{2}$ and selective catalytic/non-catalytic reduction (SCR/SNCR) control for $\mathrm{NO}_{2}$ were widely installed on stationary source, which generally have a similar effectiveness in pollution removal ratio ( $>80 \%$, $\mathrm{MEP}, 2005,2010)$. Thus, the $\mathrm{SO}_{2} / \mathrm{NO}_{2}\left(\mathrm{SO}_{2}\right.$ stationary/ $\left(\mathrm{NO}_{2}\right.$ mobile $+\mathrm{NO}_{2}$ stationary $\left.)\right)$ ratio should be more sensitive to the relative effectiveness of mobile source control. The pollution roses for the $\mathrm{SO}_{2} / \mathrm{NO}_{2}$ ratio at the same station in Shanghai for 2009 and 2010 are plotted in Figs. $2(\mathrm{~g})-2(\mathrm{i}))$. The $\mathrm{SO}_{2} / \mathrm{NO}_{2}$ ratio at a moderate to high wind speeds was generally higher than 1.2 in 2009 (Fig. 2(g)), indicating more $\mathrm{SO}_{2}$ than $\mathrm{NO}_{2}$ came from regional or super-regional transport. The $\mathrm{SO}_{2} / \mathrm{NO}_{2}$ ratio at almost all speeds and directions decreased to below 1 in 2010 (Fig. 2(h)), which indicates stronger control of $\mathrm{SO}_{2}$ emissions from stationary sources than of $\mathrm{NO}_{x}$ emissions from mobile sources both in the local and regional areas. The analysis results for $\mathrm{NO}_{2}$ and the $\mathrm{SO}_{2} / \mathrm{NO}_{2}$ ratio suggest that the increase in $\mathrm{NO}_{2}$ from non-wind factors possibly due to the ineffective mobile emission control. This failure control is also supported by Lin et al. (2013b). They found a $\mathrm{NO}_{2}$ had higher correlations with $\mathrm{PM}_{2.5}$ than $\mathrm{SO}_{2}$, indicating mobile source contributed a lot to local $\mathrm{NO}_{2}$ emission. Huang et al. (2013) also showed that the stationary source in Shanghai had less contribution to heavy $\mathrm{NO}_{2}$ and CO pollution; organic matter and black carbon contributed a lot to $\mathrm{PM}_{1}$ (Huang et al., 2012), which closely related to 


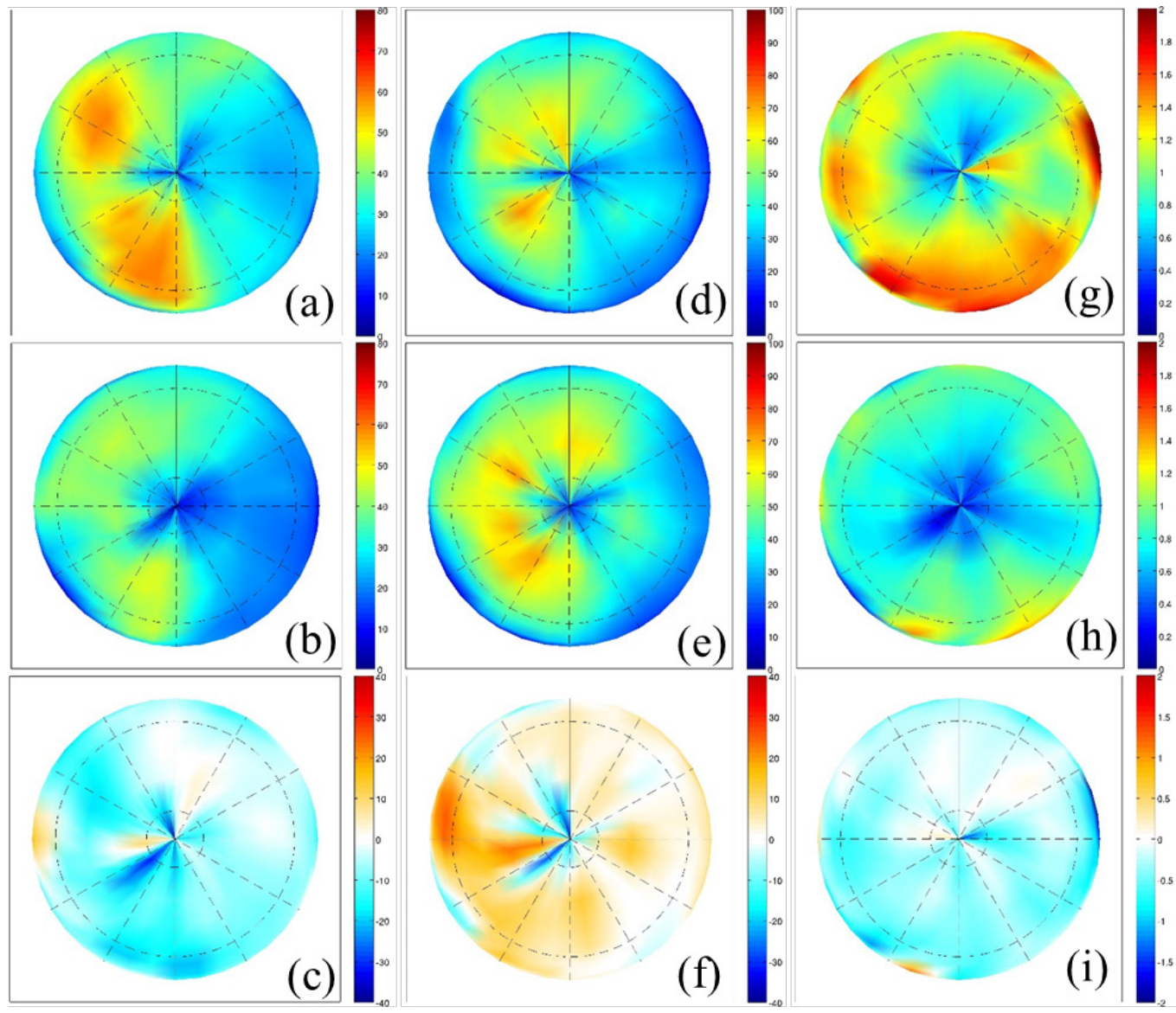

Fig. 2. Pollution roses at rural site of Shanghai (a) $\mathrm{SO}_{2}$ of 2009 (unit: ppb), (b) $\mathrm{SO}_{2}$ of 2010 (unit: ppb), (c) $\mathrm{SO}_{2}$ difference of 2010-2009 (unit: ppb); (d) $\mathrm{NO}_{2}$ of 2009 (unit: ppb), (e) $\mathrm{NO}_{2}$ of 2010 (unit: ppb), (f) $\mathrm{NO}_{2}$ difference of 2010-2009 (unit: ppb); (g) $\mathrm{SO}_{2} / \mathrm{NO}_{2}$ of 2009 (unitless), (h) $\mathrm{SO}_{2} / \mathrm{NO}_{2}$ of 2010 (unitless), (i) $\mathrm{SO}_{2} / \mathrm{NO}_{2}$ difference of 2010-2009 (unitless); The small circle represents the $2 \mathrm{~m} \mathrm{~s}^{-1}$ wind speed and the large circle represents the $8 \mathrm{~m} \mathrm{~s}^{-1}$ wind speed.

vehicular emission. $\mathrm{NO}_{2}$ control during the Expo period may have failed: though the emission standard for on-road traffic was updated before the Expo, no actions such as those taken for Beijing Olympics were taken for $\mathrm{NO}_{2}$ control. Therefore, the uncontrolled traffic emissions and the tremendous number of visitors to the Expo are likely the reasons for the increase in $\mathrm{NO}_{\mathrm{x}}$ emissions at urban areas during the Shanghai Expo.

\subsection{Analysis for 2008 Beijing Olympics}

In this section, we used the WPD method to quantify the meteorology-driven and emissiondriven impacts on changes in pollution concentrations in Beijing during the period of the Olympics ( 1 July-31 August) in 2008 compared with the corresponding period in 2007. Although limited data were available for the Beijing Olympics event, we were still able to quantify the $\mathrm{PM}$ and $\mathrm{NO}_{\mathrm{x}}$ trends. Hourly $\mathrm{NO}_{x}$ and $\mathrm{PM}_{2.5}$ measurements taken at the Peking University station. Table 2 shows the decomposition results. Mean concentration for all pollutants during the Olympic period in 2008 are lower than the corresponding period in 2007. In particular, reduced concentrations of $\mathrm{NO}_{\mathrm{x}}$ (13.02 ppb) and $\mathrm{PM}_{2.5}\left(59.13 \mu \mathrm{g} \mathrm{m}^{-3}\right.$ ) are excellent. The confidence level (the linear index C-L) for all pollutants are equal to 0.99 , indicating our confidence in the results (i.e., the linear decomposition results did not happen by chance for $99 \%$ possibility). According to the results, both meteorologydriven and emission-driven effects contributed to air quality improvement during the Olympics. Specifically, the emission-driven effect contributed as much as $86 \%$ and $94 \%$ of the $\mathrm{NO}_{\mathrm{x}}$ and $\mathrm{PM}_{2.5}$ concentration reductions respectively, while meteorology effect contributed approximately $16 \%$ and $4 \%$ respectively. 
Table 2. The decomposition result of primary pollutants in Beijing for the Olympic period (July 1August 31) in 2008 compared with the corresponding time in 2007.

\begin{tabular}{lll}
\hline Name & $\mathrm{NO}_{\mathrm{x}}$ & $\mathrm{PM}_{2.5}$ \\
\hline$C 1$ & 36.75 & 131.71 \\
$\Delta C$ & -13.02 & -59.13 \\
Non-wind effect & $-86 \%(-11.35)$ & $-94 \%(-55.58)$ \\
Wind effect & $-16 \%(-2.08)$ & $-4 \%(-2.36)$ \\
Nonlinear effect & $3 \%$ & $-2 \%$ \\
$L$ index & 0.98 & 0.98 \\
$C-L$ & 0.99 & 0.99 \\
\hline
\end{tabular}

Note: The $C 1$ and $\Delta C$ unit for $\mathrm{NO}_{\mathrm{x}}$ is $\mathrm{ppb}$, and it is $\mu \mathrm{g} \mathrm{m}^{-3}$ for $\mathrm{PM}_{2.5} . C 1$ means the averaged concentration of pre-control period. Years with negative $\Delta C$ mean that the annual mean $\mathrm{PM}_{10}$ concentration deceased compared to the previous year, and vice versa. If the decomposed effect has a same sign with the $\Delta C$, it means the effect of this factor play a positive role on the pollution change, and vice versa. " $C-L$ " indices are the confidence level from the Monte Carlo simulation and dimensionless.

The significant emission-driven contribution to the reduction in $\mathrm{PM}_{2.5}$ pollution $(59.13 \times 94 \%$ $=55.58 \mu \mathrm{g} \mathrm{m}^{-3}$ ) suggests an effective control during the Beijing Olympics. Various measures were taken to reduce emissions, including closing or relocating industrial plants, decreasing local power generation, suspending construction, promoting natural gas usage, and implementing strict traffic (e.g., the odd/even license plate number rule was applied to personal vehicles in Beijing). The effectiveness of the emission-driven effect can be derived with itself in concentration format (Non-wind effect $\times \Delta \mathrm{C}$ ) divided by mean concentration of the same period in 2007 (C1), which is $42 \%$ for $\mathrm{PM}_{2.5}$ and $31 \%$ for $\mathrm{NO}_{2}$. These effectiveness coincide well with other numerical simulation studies. Gao et al. (2011) used WRF-Chem to investigate the effectiveness of government control during Olympics. Their result shows a $43 \%$ emission-driven reduction for $\mathrm{PM}_{2.5}$. Xing et al. (2011) also applied a WRF-CMAQ model to simulate the emission control impact during Olympics. Result shows a 16-48\% emission-driven reduction for $\mathrm{PM}_{2.5}$ and a $16-32 \%$ reduction for $\mathrm{NO}_{2}$ in urban area. Those results demonstrate Beijing had an effective emission control during the Olympics and emission-driven cleaning is dominating effect on air quality improvement.

However, $\mathrm{PM}_{10}$ and $\mathrm{PM}_{2.5}$ exceeding were still recorded by Wang et al. (2010) for many days during the Olympics, despite the aggressive emission restrictions were implemented via a JJ regional-joint control regardless of economic losses. This outcome reveal a substantial challenge of meeting air quality standards in Beijing and the JJJ region, due to the high national background of $\mathrm{PM}_{2.5}$. The average $\mathrm{PM}_{2.5}$ concentration in Beijing was $42 \mu \mathrm{g} \mathrm{m}^{-3}$ in 2019 , much lower than the $\mathrm{PM}_{2.5}$ concentration during the Olympics $\left(72.58 \mu \mathrm{g} \mathrm{m}^{-3}\right)$ and its corresponding period in 2007 $\left(131.71 \mu \mathrm{g} \mathrm{m}^{-3}\right)$. Up to now, a great success has been achieved by PM emission control, resulting a more environmental-friendly society that catch up with the Eleventh Five-Year Plan (MEP, 2006).

\subsection{Analysis for 2010 Guangzhou Asian Games}

For the Guangzhou Asian Games, the WPD analysis was performed on $\mathrm{SO}_{2}, \mathrm{NO}_{2}$, and $\mathrm{PM}_{10}$ pollution at Luhu station for the period of 1 October to 31 December in 2009 and 2010. The quantification results are provided in Table 3. The confidence level of all decomposition results is higher than 90\%. During the Asian Games, seven major air pollution control measures were carried out in Guangzhou and nearby cities: limiting emissions from thermal power plants, supervising heavily polluting factories, implementing traffic restrictions, restricting marine vessel voyages, fugitive dust control, volatile organic compound control, and restaurant emission control.

The negative emission-driven effect on $\mathrm{PM}_{10}\left(-25.66 \mu \mathrm{g} \mathrm{m}^{-3}\right)$ and $\mathrm{SO}_{2}(-0.60 \mathrm{ppb})$ pollution indicates the effectiveness control of emissions measures for fugitive dust and coal combustionrelated sources such as power plants and factories. Although the mean concentration of $\mathrm{NO}_{\mathrm{x}}$ reduced by $0.83 \mathrm{ppb}$, the decomposition result shows that the emission-driven effect of $\mathrm{NO}_{2}$ increased by $1.98 \mathrm{ppb}$ in 2010. Instead, meteorology-driven effect caused the observed reduction in $\mathrm{NO}_{x}$ during the Guangzhou Asian Games. The aggravation of emission-driven $\mathrm{NO}_{2}$ and $\mathrm{O}_{3}$ implies that the implemented strategies were not effective, despite the conventional traffic 
Table 3. Decomposition result of pollution variation between consecutive fall season period (September 1-November 31) of 2009 and 2010 at Guangzhou.

\begin{tabular}{llllll}
\hline Year 2010 fall-2009 fall & $\mathrm{SO}_{2}$ & $\mathrm{NO}_{2}$ & $\mathrm{PM}_{10}$ & $\mathrm{O}_{3}$ & $\mathrm{O}_{\mathrm{x}}$ \\
\hline$C 1$ & 11.52 & 33.10 & 97.90 & 26.53 & 58.29 \\
$\Delta C$ & -1.53 & -0.83 & -25.66 & 15.24 & 15.69 \\
Non-wind effect & $-39 \%(-0.60)$ & $238 \%(1.98)$ & $-92 \%(-23.6)$ & $105 \%(16.00)$ & $114 \%(17.89)$ \\
Wind effect & $-51 \%(-0.78)$ & $-357 \%(-2.96)$ & $-3 \%(-0.77)$ & $-5 \%(-0.76)$ & $-5.5 \%(-0.86)$ \\
Nonlinear effect & $-10 \%$ & $19 \%$ & $-5 \%$ & $0 \%$ & $-8.5 \%$ \\
$L$ index & 0.90 & 0.97 & 0.95 & 1.00 & 0.93 \\
$C-L$ & 0.93 & 0.99 & 0.97 & 0.99 & 0.96 \\
\hline
\end{tabular}

Note: The unit of $C 1$ and $\Delta C$ for $\mathrm{SO}_{2}, \mathrm{NO}_{2}, \mathrm{O}_{3}$ and $\mathrm{O}_{\mathrm{x}}$ are $\mathrm{ppb}$, while the unit of $\Delta C$ for $\mathrm{PM}_{10}$ is $\mu g \mathrm{~m}^{-3}$. $C 1$ means the averaged concentration of pre-control period. Years with negative $\Delta C$ mean that the annual mean $\mathrm{PM}_{10}$ concentration deceased compared to the previous year, and vice versa. If the decomposed effect has a same sign with the $\Delta C$, it means the effect of this factor play a positive role on the pollution change, and vice versa. "C- $L$ " indices are the confidence level from the Monte Carlo simulation and dimensionless.

restrictions also prohibit heavily polluted vehicles (vehicles with yellow signs) going on road. This meteorology-driven exacerbation is in line with the study of Lu et al. (2013), which revealed that, during the Asian Game, the largest contributor of $\mathrm{NO}_{x}$ was on-road mobile source while vehicular emission control might be inefficient for $\mathrm{NO}_{2}$ reduction. This analysis shows an example that the absolute pollution reduction does not guarantee with the positive effectiveness of emission control. In summary, wind effects led to reductions (3\%-357\%) in the concentrations of the primary pollutants in fall 2010 compared to fall 2009, while emission-driven effect has a cleaning impact on $\mathrm{SO}_{2}$ and $\mathrm{PM}_{10}$ but an aggravation on $\mathrm{NO}_{2}$. These results indicate that the control policies during the Guangzhou Asian Games were effective only for $\mathrm{SO}_{2}$ and $\mathrm{PM}_{10}$ pollution (Tao et al., 2015) but not for $\mathrm{NO}_{2}$ pollution which is similar to Shanghai Expo.

\subsection{Analysis for 2020 Wuhan Lockdown}

The WPD method was also applied to quantify the emission-driven and meteorology-driven effects on air quality during the COVID-19 lockdown period in Wuhan. We selected the period from 23 January to 10 March in 2020, and compared it to the same period in 2019. Hourly air quality data $\left(\mathrm{PM}_{2.5}, \mathrm{NO}_{2}, \mathrm{SO}_{2}, \mathrm{O}_{3}\right.$ and $\mathrm{O}_{3} \_$h) were obtained from two stations selected based on the prevailing northeast wind direction in Wuhan. $\mathrm{O}_{3} \_\mathrm{h}$ is the mean ozone concentration in the previous 8 hours. Ganghua station (in Qingshan District) and Moon Lake station (in Hanyang District) were selected (see Fig. S1 in Supporting Information for map). Ganghua Station located in the northeast corner of downtown Wuhan, and Moon Lake Station is located at the center of downtown Wuhan. Table 4 shows the decomposition results comparing the selected period with the corresponding period in 2019. Significant reductions are observed in the mean concentrations of all pollutants except $\mathrm{O}_{3}$ and $\mathrm{O}_{3}$-8h. The non-wind effect, mainly driven by local emissions, made the dominant contribution of $99 \%-147 \%$ to the observed pollution reduction. $L$ index of all pollutants ranged from 0.91 to 0.99 , indicating the reliability of the decomposition results. The mean $\mathrm{PM}_{2.5}$ concentration during the selected period in 2019 are $79.43 \mu \mathrm{g} \mathrm{m}^{-3}$ at Ganghua Station and $70.98 \mu \mathrm{g} \mathrm{m}^{-3}$ at Moon Lake Station, with a decrease for $28.28 \mu \mathrm{g} \mathrm{m}^{-3}$ and $38.84 \mu \mathrm{g} \mathrm{m}^{-3}$ respectively. But the wind effect did not substantially lower the $\mathrm{PM}_{2.5}$ concentration, even aggravated the $\mathrm{SO}_{2}$ and $\mathrm{NO}_{2}$. The contaminating wind effect indicates a regional transport contribution, which is supported by Lian et al. (2020)'s study. Zhang et al. (2020) further indicated this transport is a result of relative high-polluted level of the surrounding provinces, due to more anthropogenic activities (Lian et al., 2020; Zhang et al., 2020). The emission-driven effect was close to $100 \%$ or $>100 \%$, indicating the significant emission-driven impact on air quality improvement during the COVID-19 lockdown. A noticeable fact is that, significant reduction of $\mathrm{NO}_{\mathrm{x}}$ and $\mathrm{PM}_{2.5}$ appeared together with an enhancement of $\mathrm{O}_{3}$, especially in urban region, which could be on the score of weakened $\mathrm{NO}_{x}$-titration effect (Li et al., 2013b; Le et al., 2020), weakened uptakes of $\mathrm{HO}_{2}$ radicals (Li et al., 2019), and increased photolysis rate due to the significant $\mathrm{PM}_{2.5}$ reduction (Gao et al., 2020). Increasing $\mathrm{O}_{3}$ concentration could lead to an enhancement of atmospheric oxidability and 
Table 4. Decomposition result during Wuhan lockdown (23 January-10 March, 2020) compared to the corresponding period of 2019.

\begin{tabular}{|c|c|c|c|c|c|c|c|c|c|c|}
\hline Station & Ganghua & Ganghua & Ganghua & Ganghua & Ganghua & $\begin{array}{l}\text { Moon } \\
\text { Lake }\end{array}$ & $\begin{array}{l}\text { Moon } \\
\text { Lake }\end{array}$ & $\begin{array}{l}\text { Moon } \\
\text { Lake }\end{array}$ & $\begin{array}{l}\text { Moon } \\
\text { Lake }\end{array}$ & $\begin{array}{l}\text { Moon } \\
\text { Lake }\end{array}$ \\
\hline Pollutant & $\mathrm{PM}_{2.5}$ & $\mathrm{NO}_{2}$ & $\mathrm{SO}_{2}$ & $\mathrm{O}_{3}$ & $\mathrm{O}_{3} \_\mathrm{h}$ & $\mathrm{PM}_{2.5}$ & $\mathrm{NO}_{2}$ & $\mathrm{SO}_{2}$ & $\mathrm{O}_{3}$ & $\mathrm{O}_{3} \_\mathrm{h}$ \\
\hline$C 1$ & 79.43 & 21.93 & 4.09 & 18.84 & 18.84 & 70.98 & 24.34 & 3.11 & 15.98 & 16.05 \\
\hline$\Delta C$ & -28.28 & -10.03 & -0.70 & 9.41 & 9.41 & -38.84 & -15.68 & -0.56 & 11.94 & 11.86 \\
\hline Non-wind effect & $\begin{array}{l}-101 \% \\
(-28.44)\end{array}$ & $\begin{array}{l}-99 \% \\
(-9.92)\end{array}$ & $\begin{array}{l}-147 \% \\
(-1.03)\end{array}$ & $\begin{array}{l}76 \% \\
(7.17)\end{array}$ & $\begin{array}{l}85 \% \\
(7.95)\end{array}$ & $\begin{array}{l}-100 \% \\
(-38.66)\end{array}$ & $\begin{array}{l}-100 \% \\
(-15.62)\end{array}$ & $\begin{array}{l}-133 \% \\
(-0.74)\end{array}$ & $\begin{array}{l}85 \% \\
(10.11)\end{array}$ & $\begin{array}{l}90 \% \\
(10.63)\end{array}$ \\
\hline Wind effect & $\begin{array}{l}-6 \% \\
(-1.81)\end{array}$ & $\begin{array}{l}3 \% \\
(0.34)\end{array}$ & $\begin{array}{l}52 \% \\
(0.37)\end{array}$ & $\begin{array}{l}22 \% \\
(2.04)\end{array}$ & $\begin{array}{l}17 \% \\
(1.55)\end{array}$ & $\begin{array}{l}-12 \% \\
(-4.52)\end{array}$ & $\begin{array}{l}-1 \% \\
(-0.227)\end{array}$ & $\begin{array}{l}24 \% \\
(0.14)\end{array}$ & $\begin{array}{l}16 \% \\
(1.95)\end{array}$ & $\begin{array}{l}12 \% \\
(1.45)\end{array}$ \\
\hline Nonlinear effect & $7 \%$ & $-4 \%$ & $-5 \%$ & $2 \%$ & $-1 \%$ & $11 \%$ & $1 \%$ & $9 \%$ & $-1 \%$ & $-2 \%$ \\
\hline$L$ index & 0.94 & 0.96 & 0.97 & 0.98 & 0.99 & 0.91 & 0.99 & 0.95 & 0.99 & 0.98 \\
\hline$C-L$ & 0.97 & 0.98 & 0.99 & 0.99 & 1.00 & 0.94 & 0.99 & 0.97 & 1.00 & 0.99 \\
\hline
\end{tabular}

Note: The $\mathrm{C} 1$ and $\Delta C$ unit for $\mathrm{O}_{3}, \mathrm{O}_{3} \_\mathrm{h}, \mathrm{NO}_{2}$, and $\mathrm{SO}_{2}$ is $\mathrm{ppb}$, and it is $\mu \mathrm{g} \mathrm{m}^{-3}$ for $\mathrm{PM}_{2.5}$. $\mathrm{O}_{3}$ _ $8 \mathrm{~h}$ means mean concentration of ozone for previous 8 hours. $C 1$ means the averaged concentration of pre-control period. Years with negative $\Delta C$ mean that the annual mean pollutant concentration deceased compared to the previous year, and vice versa. If the decomposed effect has a same sign with the $\Delta C$, it means the effect of this factor play a positive role on the pollution change, and vice versa. " $C-L$ " indices are the confidence level from the Monte Carlo simulation and dimensionless.

production of secondary aerosol especially in the urban area (Le et al., 2020), although it is not exceeding the air quality standard.

\subsection{Implication of Event Comparisons}

To compare the different events, the decomposition results of the different events are shown in Table 5. The effectiveness of the emission change during Wuhan Lockdown was the most effective (64\% $\mathrm{NO}_{2}$ and $54 \% \mathrm{PM}_{2.5}$ reductions due to nearly complete emissions shutdown), followed by the Beijing Olympics (42\% $\mathrm{PM}_{2.5}$ and $31 \% \mathrm{NO}_{2}$ reductions); the Shanghai Expo and the Guangzhou Asian Games showed $24 \%$ and $10 \%$ emission-driven reductions in PM pollution, respectively.

A negligible emission-driven $\mathrm{NO}_{2}$ reduction during the Expo event and an increased emissiondriven effect (6\%) for $\mathrm{NO}_{2}$ pollution during the Guangzhou Asian Games indicate that the strategies applied for $\mathrm{NO}_{x}$ control from on-road vehicles are not as effective as those applied for PM and $\mathrm{SO}_{2}$, further indicating the traffic restriction impact on emission control is not as thorough as construction suspension and industry shutdown. Compared with Wuhan Lockdown that almost no vehicles on road, partial traffic restriction in Asian Game and World Expo is not fully effective to control $\mathrm{NO}_{\mathrm{x}}$. The results imply that further $\mathrm{NO}_{\mathrm{x}}$ reductions will require more effective control measures (e.g., further improve the fuel quality, promote green cars) than just prohibiting some vehicles from being on the road.

Large regional pollution transport can still be found in some events (e.g., Wuhan and Shanghai), which indicate a stronger regional-joint prevention for emission control is highly required to completely improve air quality. Beijing had a better regional control because air quality improvement was observed in nearby cities, Tianjin and Shijiazhuang (Mijling et al., 2009). The two Olympic Game have similar control strategies but differ from effectiveness (E_ratio of PM: Beijing 42\% and Guangzhou 24\%). The reason is Beijing has stronger regional-joint control strategies and a more strict regulation of factory closure, of which hundreds shutdown or relocation were implemented than that for Guangzhou. The COVID-19 case shows a largest impact of E_ratio among all events, which should be achieved by shutting down majority of the emission sources, not only Wuhan but almost nationwide (Le et al., 2020). However, the impact on air quality improvement are not as effective as expected with such an extreme emission closure. The concentration of $\mathrm{PM}_{2.5}$ in Wuhan Lockdown is very close to the national-II air quality standard (NAQS-II, $35 \mu \mathrm{g} \mathrm{m}^{-3}$ ), which may convey the enormous difficulty of attaining the NAQS-II at a normal (non-lockdown) condition.

In addition, emission-driven effects increased ozone levels during the Wuhan Lockdown and the Guangzhou Asian Games. Despite the significant reduction (64\%) in $\mathrm{NO}_{2}$ during the Wuhan Lockdown, the mean ozone showed a $>60 \%$ increase compared to 2019 . Though the average 
Table 5. Comparison of the decomposition results of the four events.

\begin{tabular}{|c|c|c|c|c|c|}
\hline & & Beijing Olympic Games & Shanghai World Expo & Guangzhou Asian Games & Wuhan COVID-19 Lockdown \\
\hline \multirow[t]{4}{*}{ PM } & $C 1$ & 131.71 & 77.44 & 97.90 & 70.98 \\
\hline & $\Delta C$ & -59.13 & -7.56 & -25.66 & -38.84 \\
\hline & Non-wind effect & $-94 \%(-55.58)$ & $-104 \%(-7.86)$ & $-92 \%(-23.6)$ & $-100 \%(-38.66)$ \\
\hline & $E_{\text {_ratio }}{ }^{a}$ & $-42 \%^{b}$ & $-10 \%^{c}$ & $-24 \%^{c}$ & $-54 \%^{b}$ \\
\hline \multirow[t]{4}{*}{$\mathrm{SO}_{2}$} & $C 1$ & & 29.5 & 11.52 & 3.11 \\
\hline & $\Delta C$ & & -4.9 & -1.53 & -0.56 \\
\hline & Non-wind effect & & $-85 \%(-4.17)$ & $-39 \%(-0.60)$ & $-133 \%(-0.74)$ \\
\hline & E_ratio ${ }^{a}$ & & $-14 \%$ & $-5 \%$ & $-24 \%$ \\
\hline \multirow[t]{4}{*}{$\mathrm{NO}_{2}$} & $C 1$ & 36.75 & 47.91 & 33.10 & 24.34 \\
\hline & $\Delta C$ & -13.02 & -1.02 & -0.83 & -15.68 \\
\hline & Non-wind effect & $-86 \%(-11.35)$ & $-101 \%(-1.03)$ & $238 \%(1.98)$ & $-100 \%(-15.62)$ \\
\hline & E_ratio ${ }^{a}$ & $-31 \%$ & $-2 \%$ & $+6 \%$ & $-64 \%$ \\
\hline \multirow[t]{4}{*}{$\mathrm{O}_{3}$} & $C 1$ & & & 26.53 & 15.98 \\
\hline & $\Delta C$ & & & 15.24 & 11.94 \\
\hline & Non-wind effect & & & $105 \%(16.00)$ & $85 \%(10.11)$ \\
\hline & E_ratio ${ }^{a}$ & & & $+60 \%$ & $+63.2 \%$ \\
\hline
\end{tabular}

Note: The $\mathrm{C} 1$ and $\Delta C$ unit for $\mathrm{O}_{3}$ and $\mathrm{NO}_{2}$ is $\mathrm{ppb}$, and it is $\mu \mathrm{g} \mathrm{m}^{-3}$ for PM. $C 1$ means the averaged concentration of pre-control period. Years with negative $\Delta C$ mean that the annual mean pollutant concentration deceased compared to the previous year, and vice versa. If the decomposed effect has a same sign with the $\Delta C$, it means the effect of this factor play a positive role on the pollution change, and vice versa. The number in the first line of non-wind effect is the percentage increase (positive value) or reduction (negative value). The second line inside brackets is the concentration changes of non-wind effect in corresponding unit, their sign means increase or reduction. E_ratio ${ }^{a}$ is the effectiveness of the emission-driven effect $=$ absolute non-wind effect/C1. ${ }^{b}$ derived from the $\mathrm{PM}_{2.5}$ pollutant. ${ }^{c}$ derived from the $\mathrm{PM}_{10}$ pollutant.

ozone level at non-lockdown period is very low (15.98-26.53 ppb) and no ozone episodes occurred during the winter, the increase in emission-driven ozone levels during Wuhan Lockdown still imply the possible ozone increases in the significant reduction case of $\mathrm{NO}_{x}$ and $\mathrm{PM}_{2.5}$. Therefore, simply shutting down all emission sources is apparently not an effective way to inhibit ozone pollution. Further understanding the behavior of the chemical and physical interaction between the ozone and $\mathrm{PM} / \mathrm{NO}_{x}$ should help us find better solution for advanced control strategies and improving future air quality.

One thing worth to be highlighted is that the WPD method provides an objective and robust tool to quantify meteorology-driven and emission-driven impacts on air quality changes at the inter-annual scale and only using routine air quality data, which is easy to be applicable for any other cites or periods. This analysis show an example of using the WPD to comparing the integrated emission control impact on the air quality among different event, which could provide insight into the future air quality management for any city.

\section{UNCERTAINTIES AND LIMITATIONS}

We note that the decomposed wind-driven effect for primary pollutants may not be exactly equal to the meteorological impact on air quality, which also includes variations in wet deposition due to precipitation changes; chemical reaction rate related to solar radiation intensity; hygroscopic particle growth related to humidity, and etc. However, the derived wind-driven effect is not only reflect the impact of wind change, but also the impact due to the change of other meteorological parameters varying at the same time, since the wind and other parameters frequently vary together. For example, the PM pollution will be dissipated when the temperature and relative humidity decrease and northerly wind strengthened in wintertime in Beijing. Therefore, the winddriven effect can be applied as an indicator for the dominating meteorological impact when treating such a short period, especially for $\mathrm{NO}_{2}$ and $\mathrm{SO}_{2}$.

To estimate the uncertainties of using wind-driven effect to represent the meteorology-driven effect, we also include several related meteorology parameters (including temperature, relative 
Table 6. Decomposition result during Wuhan lockdown (January 23-March 10, 2020) applied on WPD (wind only) and improved WPD with other meteorological parameters.

\begin{tabular}{lllll}
\hline Pollutant & & $\mathrm{PM}_{2.5}$ & & $\mathrm{NO}_{2}$ \\
\hline Method & WPD & Improved WPD & WPD & Improved WPD \\
\hline Emission effect & $-100 \%$ & $-103 \%$ & $-100 \%$ & $-103 \%$ \\
Wind/Meteorology effect & $-12 \%$ & $1 \%$ & $-1 \%$ & $8 \%$ \\
Nonlinear effect & $11 \%$ & $3 \%$ & $1 \%$ & $-5 \%$ \\
$L$ index & 0.91 & 0.98 & 0.99 & 0.95 \\
\hline
\end{tabular}

humidity and precipitation) into this decomposition analysis. By introducing multiple parameters in the wind rose grouping, sample size in each grouping decreased (e.g., if one parameter is missing, all type of data at this specific time is abandoned), and unmatched grouping pairs increased between the study period of two years (e.g., when specific wind speed/direction combinations only occur in one period, but not in the other). All of them may cause a failure of applying the decomposition analysis. To ensure the reliability of the results, analysis is only applied when the deviation of calculated expected value from the arithmetic mean is less than $5 \%$. Due to this issues, some of those failed to derive decomposition results by the improved WPD analysis. Fortunately, some of results are satisfying the criterion and statistically valid.

Table 6 shows the result of WPD analysis and the improved WPD analysis by combing other meteorological parameters in Wuhan Lockdown. As shown, emission effect derived from the two methods are very close, of which difference are smaller than $3 \%$. The change of non-wind term and nonlinear term are around $10 \%$ in this case, probably due to better representative of meteorological effect or the uncertainties caused by limited data size, which we do not discuss further in this analysis. Other valid results also show that the non-wind effects are quite stable from the two analysis (not shown). The stable non-wind effect indicate that the derived non-wind effect is a reasonable approximation of the non-meteorology-driven effect (i.e., emission-driven effect) in these events. Concentration variations might attribute to (1) the wind-driven effect also include meteorological effects induced by parameters other than wind, which frequently varies with the wind concurrently (e.g. In Beijing, the northerly generally bring cold and dry airmass; In Guangzhou, the southerly generally bring warm and moisture airmass); (2) the sensitivity of other meteorological parameters is less than wind variations in these short events during such short periods; (3) the dominant role of the emission-driven impact with enforced emission reduction in the four events. However, the representativeness of wind-driven effect for meteorology-driven effect at other cities and long-term analysis should be further examined. The further improvement should be carried out for the method to be applied to evaluate meteorology-driven effect on the year-to-year air quality variation in the future.

\section{CONCLUSIONS}

In this study, to assess effectiveness of the emission control strategies have been carried out in China, we used the WPD method to quantify the effectiveness of the integrated control programmes implemented for the largest three international social events as well as the passive emission reduction during the COVID-19 Lockdown in Wuhan. The emission-driven and meteorology-driven impacts on the observed air quality changes during these events were quantified and compared based on the best available observational data. Based on the quantified results with this objective and robust method, we first compare the control effectiveness of the different mega-events together.

The emission-driven factor generally had the most important role in significant pollution variations (> 86\%). The emission-driven pollution reduction was largest in the Wuhan Lockdown (64\% $\mathrm{NO}_{2}$ and $54 \% \mathrm{PM}_{2.5}$ reductions), followed by Beijing Olympics (42\% $\mathrm{PM}_{2.5}$ and $31 \% \mathrm{NO}_{2}$ reductions) and smallest in the longest lasting Shanghai Expo event. Shutdown or emission control measures applied to industries and power plants are significantly effective for $\mathrm{SO}_{2}, \mathrm{NO}_{2}$ and $\mathrm{PM}_{2.5}$ reduction, but those applied to on-road traffic control are less-effective for reducing $\mathrm{NO}_{2}$, even not works for $\mathrm{O}_{3}$ reduction. The Wuhan COVID-19 (with such an extreme emission 
reduction) impact on air quality improvement was not as effective as expected especially for $\mathrm{O}_{3}$, which further implies the difficulty of air quality attainment in case of non-lockdown. There were also several specific failures that are worth highlighting. (1) During the Shanghai Expo event, the decomposition results revealed that the emission-driven factors played a positive role in air quality improvement (108\%-85\% removal) for most stations and pollutants, but except for urban $\mathrm{NO}_{2}$ pollution due to less-effective control for on-road traffic as well as the massive number of visitors' vehicles. (2) Though the mean value of $\mathrm{PM}_{10}$ decreased significantly from 2009 to 2010, the positive emission-driven contribution from the southeast indicated the failed control of biomass burning during the summer of 2010, despite the prohibition on open biomass burning was a regional-joint control statute (by Shanghai, Jiangsu, and Zhejiang governments) during the Expo period, which suggests that the ongoing supervision of control strategies is a key issue to air quality management in future. (3) A decrease of mean $\mathrm{NO}_{2}$ concentration was observed $(0.83$ $\mathrm{ppb}$ ) during the Guangzhou event, but the decomposition results revealed that the reduction in $\mathrm{NO}_{2}$ was due to the wind effect; the emission-driven effect on $\mathrm{NO}_{2}$ actually aggravated pollution by 1.98 ppb in 2010, which indicates the failure for $\mathrm{NO}_{2}$ control in Guangzhou (same as Shanghai). (4) The applied control strategies seem to be less-effective, at least ineffective for ozone. In terms of future air quality management in China, the reduction of on-road exhaust emission and ozone pollution is one of the major challenges. It is necessary to introduce advanced control measures for vehicle exhaust, and implement control strategies considering the chemical and physical coupling between ozone and $\mathrm{NO}_{x} / \mathrm{VOC} / \mathrm{PM}$.

\section{ACKNOWLEDGEMENT}

This research supported by the National Natural Science Foundation of China (Grant No. 41961160728 and 41575106), the Guangdong Basic and Applied Basic Research Fund Committee (2020B1515130003), Shenzhen Science and Technology Program (KQTD20180411143441009), Guangdong Province Science and Technology Planning Project of China (Grant 2017A050506003), Key Special Project for Introduced Talents Team of Southern Marine Science and Engineering Guangdong Laboratory (Guangzhou) (GML2019ZD0210), and Shenzhen Key Laboratory Foundation (ZDSYS20180208184349083). We also thank the Dr. Jacky Fu from Shanghai Environment Monitoring Center and Dr. Tong Zhu for providing the data for the study.

\section{DISCLAIMER}

On behalf of all authors, the corresponding author states that there is no conflict of interest.

\section{SUPPLEMENTARY MATERIAL}

Supplementary material for this article can be found in the online version at https://doi. org/10.4209/aaqr.200644

\section{REFERENCES}

Bherwani, H. (2020). Valuation of air pollution externalities: Comparative assessment of economic damage and emission reduction under COVID-19 lockdown. Air Qual. Atmos. Health 13, 683-694. https://doi.org/10.1007/s11869-020-00845-3

Chen, Yuan, Schleicher, N., Chen, Yizhen, Chai, F., Wang, S., Norra, S. (2013). The Effect of Government Policies on the Temporal Development of Contamination Characteristics Within the Aerosol Distribution in Beijing, China, in: Rauch, S., Morrison, G., Norra, S., Schleicher, N. (Eds.), Urban Environment, Springer Netherlands, Dordrecht, pp. 313-321. https://doi.org/10. 1007/978-94-007-7756-9_27

Cheng, Z., Wang, S., Jiang, J., Fu, Q., Chen, C., Xu, B., Yu, J., Fu, X., Hao, J. (2013). Long-term trend of haze pollution and impact of particulate matter in the Yangtze River Delta, China. Environ. Pollut. 182, 101-110. https://doi.org/10.1016/j.envpol.2013.06.043 
Chung, K.K., Chan, J.C.L., Ng, C.N., Lam, K.S., Wang, T. (1999). Synoptic conditions associated with high carbon monoxide episodes at a coastal station in Hong Kong. Atmos. Environ. 33, 30873095. https://doi.org/10.1016/S1352-2310(97)00328-2

Fu, Q.Y., Wei, H.P., Huang, Y.M, Gao, S., Duan, Y.S., Zhang, Y.H. (2011). Characteristics on Air Quality during the 2010 Shanghai Expo. The $7^{\text {th }}$ Asian Aerosol Conference, $X i^{\prime}$ an, China.

Gao, J., Li, Y., Zhu, B., Hu, B., Wang, L., Bao, F. (2020). What have we missed when studying the impact of aerosols on surface ozone via changing photolysis rates? Atmos. Chem. Phys. 20, 10831-10844. https://doi.org/10.5194/acp-20-10831-2020

Gao, X., Nie, W., Xue, L., Wang, T., Wang, X., Gao, R., Wang, W., Yuan, C., Gao, J., Ravi, K.P., Wang, J., Zhang, Q. (2013). Highly time-resolved measurements of secondary ions in $\mathrm{PM}_{2.5}$ during the 2008 Beijing Olympics: The impacts of control measures and regional transport. Aerosol Air Qual. Res. 13, 367-376. https://doi.org/10.4209/aaqr.2012.04.0083

Gao, Y., Liu, X., Zhao, C., Zhang, M. (2011). Emission controls versus meteorological conditions in determining aerosol concentrations in Beijing during the 2008 Olympic Games. Atmos. Chem. Phys. 11, 12437-12451. https://doi.org/10.5194/acp-11-12437-2011

Gietl, J.K., Klemm, O. (2009). Analysis of traffic and meteorology on airborne particulate matter in Münster, Northwest Germany. J. Air Waste Manage. Assoc. 59, 809-818. https://doi.org/10. 3155/1047-3289.59.7.809

Hao, N., Valks, P., Loyola, D., Cheng, Y.F., Zimmer, W. (2011). Space-based measurements of air quality during the World Expo 2010 in Shanghai. Environ. Res. Lett. 6, 044004. https://doi.org/ 10.1088/1748-9326/6/4/044004

Huang, K., Zhuang, G., Lin, Y., Wang, Q., Fu, J.S., Fu, Q., Liu, T., Deng, C. (2013). How to improve the air quality over megacities in China: Pollution characterization and source analysis in Shanghai before, during, and after the 2010 World Expo. Atmos. Chem. Phys. 13, 5927-5942. https://doi.org/10.5194/acp-13-5927-2013

Huang, X.F., He, L.Y., Xue, L., Sun, T.L., Zeng, L.W., Gong, Z.H., Hu, M., Zhu, T. (2012). Highly timeresolved chemical characterization of atmospheric fine particles during 2010 Shanghai World Expo. Atmos. Chem. Phys. 12, 4897-4907. https://doi.org/10.5194/acp-12-4897-2012

Katsoulis, B.D. (1988). Some meteorological aspects of air pollution in Athens, Greece. Meteorl. Atmos. Phys. 39, 203-212. https://doi.org/10.1007/BF01030298

Le, T., Wang, Y., Liu, L., Yang, J., Yung, Y.L., Li, G., Seinfeld, J.H. (2020). Unexpected air pollution with marked emission reductions during the COVID-19 outbreak in China. Science 369, 702706. https://doi.org/10.1126/science.abb7431

Li, K., Jacob, D.J., Liao, H., Shen, L., Zhang, Q., Bates, K.H. (2019). Anthropogenic drivers of 20132017 trends in summer surface ozone in China. Proc. Natl. Acad. Sci. USA 116, 422-427. https://doi.org/10.1073/pnas.1812168116

Li, X., He, K., Li, C., Yang, F., Zhao, Q., Ma, Y., Cheng, Y., Ouyang, W., Chen, G. (2013a). PM2.5 mass, chemical composition, and light extinction before and during the 2008 Beijing Olympics: $\mathrm{PM}_{2.5}$ and light extinction in Beijing. J. Geophys. Res. 118, 12158-12167. https://doi.org/10.1002/20 13JD020106

Li, Y., Lau, A.K.H., Fung, J.C.H., Zheng, J.Y., Zhong, L.J., Louie, P.K.K. (2012a). Ozone source apportionment (OSAT) to differentiate local regional and super-regional source contributions in the Pearl River Delta region, China. J. Geophys. Res. 117, D15305. https://doi.org/10.1029/2 011JD017340

Li, Y., Lau, A., Wong, A., Fung, J. (2014). Decomposition of the wind and non-wind effects on observed year-to-year air quality variation: Wind and pollution decomposition. J. Geophys. Res. 119, 6207-6220. https://doi.org/10.1002/2013JD021300

Li, Y., Lau, A.K.H., Fung, J.C.H., Zheng, J., Liu, S. (2013b). Importance of NO control for peak ozone reduction in the Pearl River Delta region. J. Geophys. Res. 118, 9428-9443. https://doi.org/10. 1002/jgrd.50659

Li, Y.T., Deng, X.J., Fan, S.J., Wu, D., Li, F., Deng, T., Tan, H.B., Jiang, D.H. (2012b). Study on air quality and pollution meteorology conditions of Guangzhou during the 2010 Asian games. Environ. Sci. Technol. 33, 2932-2938. (in Chinese with English Abstract)

Lian, X., Huang, J., Huang, R., Liu, C., Wang, L., Zhang, T. (2020). Impact of city lockdown on the air quality of COVID-19-hit of Wuhan city. Sci. Total Environ. 742, 140556. https://doi.org/10.1 016/j.scitotenv.2020.140556 
Lin, H., Zhang, Y., Liu, T., Xiao, J., Xu, Y., Xu, X., Qian, Z., Tong, S., Luo, Y., Zeng, W., Ma, W. (2014). Mortality reduction following the air pollution control measures during the 2010 Asian Games. Atmos. Environ. 91, 24-31. https://doi.org/10.1016/j.atmosenv.2014.03.051

Lin, J.T., Pan, D., Zhang, R.X. (2013a). Trend and interannual variability of Chinese air pollution since 2000 in association with socioeconomic development: A brief overview. Atmos. Oceanic Sci. Lett. 6, 84-89. https://doi.org/10.1080/16742834.2013.11447061

Lin, Y., Huang, K., Zhuang, G., Fu, J.S., Xu, C., Shen, J., Chen, S. (2013b). Air quality over the Yangtze River Delta during the 2010 Shanghai Expo. Aerosol Air Qual. Res. 13, 1655-1666. https://doi.org/10.4209/aaqr.2012.11.0312

Liu, H., Wang, X., Zhang, J., He, K., Wu, Y., Xu, J. (2013). Emission controls and changes in air quality in Guangzhou during the Asian Games. Atmos. Environ. 76, 81-93. https://doi.org/10. 1016/j.atmosenv.2012.08.004

Liu, Y., Yuan, B., Li, X., Shao, M., Lu, S., Li, Y., Chang, C.C., Wang, Z., Hu, W., Huang, X., He, L., Zeng, L., Hu, M., Zhu, T. (2015a). Impact of pollution controls in Beijing on atmospheric oxygenated volatile organic compounds (OVOCs) during the 2008 Olympic Games: Observation and modeling implications. Atmos. Chem. Phys. 15, 3045-3062. https://doi.org/10.5194/acp-153045-2015

Liu, Z., Hu, B., Wang, L., Wu, F., Gao, W., Wang, Y. (2015b). Seasonal and diurnal variation in particulate matter $\left(\mathrm{PM}_{10}\right.$ and $\left.\mathrm{PM}_{2.5}\right)$ at an urban site of Beijing: Analyses from a 9-year study. Environ. Sci. Pollut. Res. 22, 627-642. https://doi.org/10.1007/s11356-014-3347-0

Lo, J.C.F., Lau, A.K.H., Fung, J.C.H., Chen, F. (2006). Investigation of enhanced cross-city transport and trapping of air pollutants by coastal and urban land-sea breeze circulations. J. Geophys. Res. 111, D14104. https://doi.org/10.1029/2005JD006837

Lu, Q., Zheng, J., Ye, S., Shen, X., Yuan, Z., Yin, S. (2013). Emission trends and source characteristics of $\mathrm{SO}_{2}, \mathrm{NO}_{x}, \mathrm{PM}_{10}$ and VOCs in the Pearl River Delta region from 2000 to 2009. Atmos. Environ. 76, 11-20. https://doi.org/10.1016/j.atmosenv.2012.10.062

Ministry of Environmental Protection (MEP) (2001). The tenth five-year plan. China. (in Chinese)

Ministry of Environmental Protection (MEP) (2005). Flue gas limestone/limegypsum desulfurization project technical specification of thermal power plant. China. (In Chinese)

Ministry of Environmental Protection (MEP) (2006). The eleventh five-year plan. China. (in Chinese)

Ministry of Environmental Protection (MEP) (2010). Engineering technical specification of flue gas selective non-catalytic reduction enitration for thermal power plant. China. (in Chinese)

Ministry of Environmental Protection (MEP) (2011). The twelfth five-year plan. China. (in Chinese)

Ministry of Environmental Protection (MEP) (2013). Air pollution prevention and control action plan. China. (in Chinese)

Mijling, B., van der A, R.J., Boersma, K.F., Van Roozendael, M., De Smedt, I., Kelder, H.M. (2009). Reductions of $\mathrm{NO}_{2}$ detected from space during the 2008 Beijing Olympic Games. Geophys. Res. Lett. 36, L13801. https://doi.org/10.1029/2009GL038943

Nirel, R., Dayan, U. (2001). On the ratio of sulfur dioxide to nitrogen oxides as an indicator of air pollution sources. J. Appl. Meteorol. 40, 1209-1222. https://www.jstor.org/stable/26184852

Norra, S., Yu, Y., Dietze, V., Schleicher, N., Fricker, M., Kaminski, U., Chen, Y., Stüben, D., Cen, K. (2016). Seasonal dynamics of coarse atmospheric particulate matter between $2.5 \mu \mathrm{m}$ and $80 \mu \mathrm{m}$ in Beijing and the impact of 2008 Olympic Games. Atmos. Environ. 124, 109-118. https://doi.org/10.1016/j.atmosenv.2015.08.029

Tao, J., Zhang, L., Zhang, Z., Huang, R., Wu, Y., Zhang, R., Cao, J., Zhang, Y. (2015). Control of PM2.5 in Guangzhou during the $16^{\text {th }}$ Asian Games period: Implication for hazy weather prevention. Sci. Total Environ. 508, 57-66. https://doi.org/10.1016/j.scitotenv.2014.11.074

United Nations Environment Programme (UNEP) (2009). UNEP Environmental assessment: Expo 2010 Shanghai, China. UNEP.

Wang, S., Zhao, M., Xing, J., Wu, Y., Zhou, Y., Lei, Y., He, K., Fu, L., Hao, J. (2010). Quantifying the air pollutants emission reduction during the 2008 Olympic Games in Beijing. Environ. Sci. Technol. 44, 2490-2496. https://doi.org/10.1021/es9028167

Wang, T., Lam, K.S., Lee, A.S.Y., Pang, S.W., Tsui, W.S. (1998). Meteorological and chemical characteristics of the photochemical ozone episodes observed at Cape D'Aguilar in Hong Kong. J. Appl. Meteorol. 37, 1167-1178. https://doi.org/10.1175/1520-0450(1998)037\%3C1167:MA CCOT\%3E2.0.CO;2 
Wang, W., Primbs, T., Tao, S., Simonich, S.L.M. (2009a). Atmospheric particulate matter pollution during the 2008 Beijing Olympics. Environ. Sci. Technol. 43, 6440-6440. https://doi.org/10.10 21/es901953s

Wang, X., Westerdahl, D., Chen, L.C., Wu, Y., Hao, J., Pan, X., Guo, X., Zhang, K.M. (2009b). Evaluating the air quality impacts of the 2008 Beijing Olympic Games: On-road emission factors and black carbon profiles. Atmos. Environ. 43, 4535-4543. https://doi.org/10.1016/j.atmosen v.2009.06.054

Wang, X., Wang, T., Pathak, R.K., Hallquist, M., Gao, X., Nie, W., Xue, L., Gao, J., Gao, R., Zhang, Q., Wang, W., Wang, S., Chai, F., Chen, Y. (2013). Size distributions of aerosol sulfates and nitrates in Beijing during the 2008 Olympic Games: Impacts of pollution control measures and regional transport. Adv. Atmos. Sci. 30, 341-353. https://doi.org/10.1007/s00376-012-2053-4

Wang, Y., Hao, J., McElroy, M.B., Munger, J.W., Ma, H., Chen, D., Nielsen, C.P. (2009c). Ozone air quality during the 2008 Beijing Olympics: Effectiveness of emission restrictions. Atmos. Chem. Phys. 9, 5237-5251. https://doi.org/10.5194/acp-9-5237-2009

World Bank (2015). East Asia's Changing Urban Landscape: Measuring a Decade of Spatial Growth. Washington, DC, USA.

Xing, J., Zhang, Y., Wang, S., Liu, X., Cheng, S., Zhang, Q., Chen, Y., Streets, D.G., Jang, C., Hao, J., Wang, W. (2011). Modeling study on the air quality impacts from emission reductions and atypical meteorological conditions during the 2008 Beijing Olympics. Atmos. Environ. 45, 1786-1798. https://doi.org/10.1016/j.atmosenv.2011.01.025

Xu, H.M., Tao, J., Ho, S.S.H., Ho, K.F., Cao, J.J., Li, N., Chow, J.C., Wang, G.H., Han, Y.M., Zhang, R.J., Watson, J.G., Zhang, J.Q. (2013). Characteristics of fine particulate non-polar organic compounds in Guangzhou during the $16^{\text {th }}$ Asian Games: Effectiveness of air pollution controls. Atmos. Environ. 76, 94-101. https://doi.org/10.1016/j.atmosenv.2012.12.037

Yang, L., Wu, Y., Li, J., Song, S., Zheng, X., Hao, J. (2015). Mass concentrations and temporal profiles of $\mathrm{PM}_{10}, \mathrm{PM}_{2.5}$ and $\mathrm{PM}_{1}$ near major urban roads in Beijing. Front. Environ. Sci. Eng. 9, 675-684. https://doi.org/10.1007/s11783-014-0731-4

Yao, Z., Zhang, Y., Shen, X., Wang, X., Wu, Y., He, K. (2013). Impacts of temporary traffic control measures on vehicular emissions during the Asian Games in Guangzhou, China. J. Air Waste Manage. Assoc. 63, 11-19. https://doi.org/10.1080/10962247.2012.724041

Zhang, R., Zhang, Y., Lin, H., Feng, X., Fu, T.M., Wang, Y. (2020). NO $\mathrm{N}_{\mathrm{x}}$ emission reduction and recovery during COVID-19 in East China. Atmosphere 11, 433. https://doi.org/10.3390/atmos1 1040433 